
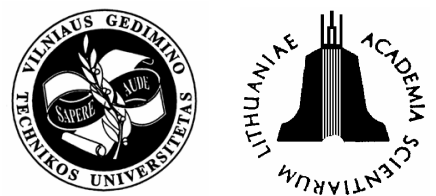

\title{
INVESTIGATION OF ROAD ACCIDENTS ON LITHUANIAN STATE ROADS
}

\author{
Vigilijus Sadauskas \\ Dept of Automobile Transport, Vilnius Gediminas Technical University, \\ J. Basanavičiaus g. 28, LT-03224 Vilnius, Lithuania. \\ E-mail:v.sadauskas@transp.lt
}

Received 14 June 2006; accepted 4 September 2006

\begin{abstract}
Fast development of the number of vehicles is closely related to large benefit for the public and also to certain undesirable large numbers of injured and killed people involved in the accidents.

What must be done? It is necessary in the nearest future to improve traffic safety situation in Lithuania. This can be reached after the detailed evaluation of accident analysis and investigations. Only a systematic and consistent approach to comprehensive traffic accident analysis can reduce the losses of lives and property in road traffic. This approach can be summarized in basic action - to establish the accident analysis and investigation groups.
\end{abstract}

Keywords: traffic safety, automobile transport, accident

\section{Introduction}

There occur some 6500 road accidents per year in Lithuania. The number varies according to the accident definitions used.

A downward in the number of accidents was achieved in Lithuania in the year 2000 [1]. This was the case especially in personal injuries, and was even more pronounced in fatal accidents. The objective in road safety work for the 2000's continued to be that of reduction in fatalities and injuries in traffic.

Distribution of road accidents and casualties in Lithuania are presented in Table.

Road accidents and casualties in Lithuania

\begin{tabular}{|c|c|c|}
\hline Year & $\begin{array}{c}\text { Road } \\
\text { accidents }\end{array}$ & Casualties \\
\hline 1991 & 6067 & 1173 \\
1992 & 4049 & 836 \\
1993 & 4319 & 958 \\
1994 & 3902 & 765 \\
1995 & 4144 & 672 \\
1996 & 4579 & 667 \\
1997 & 5319 & 725 \\
1998 & 6445 & 829 \\
1999 & 6356 & 748 \\
2000 & 5807 & 641 \\
2001 & 5972 & 706 \\
2002 & 6090 & 697 \\
2003 & 5963 & 709 \\
2004 & 6372 & 751 \\
2005 & 6790 & 760 \\
\hline
\end{tabular}

Traffic increases and is becoming more complicated. Further improvement measures have to be found and justified by means of study. In addition to the traffic system itself and traffic characteristics, research is aimed at component factors such as the driver, the vehicle and the traffic environment [2].

A possibility for gaining information and new ideas for safer traffic is through investigation of the actual accident. Information on even a single accident may provide suggestions for improvement in traffic or in the factors involved in order to prevent accidents or reduce their severity. Detailed data can be obtained on accidents, statistical findings can be explained and hypotheses can be formulated for theories.

Case studies are therefore useful in gaining detailed information on accidents in the traffic system and provide a basis for road safety work. [3].

Accident investigation structure is presented in Fig 1.

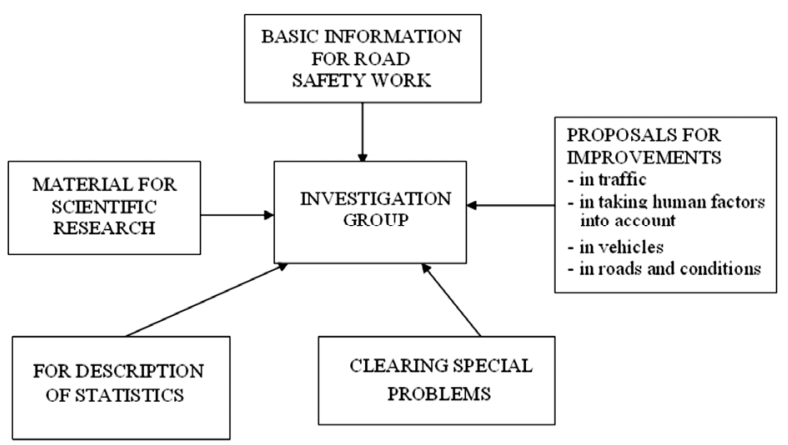

Fig 1. Accident investigation structure 


\section{Description of activities and methods}

Being in the market of insurance Lithuanian insurance companies have to be obligated to see the consequences of accidents, and they must feel very strongly about the need for investigating road accidents. Following discussions with various authorities, there is need for establishing Traffic Safety Committee.

The investigation group would be consisted of a representative of the police force, a vehicle inspector, a road safety engineer, a physician and a railway specialist. Their duties included being responsible for road safety in their area of operation. Their participation in the investigation group would be benefit for them in their normal day-to-day work by providing them with detailed and concrete information concerning road accidents [4].

To start off with, accidents leading to the death of driver or passenger will be selected as targets of investigations. The task of the investigation team will be defined as follows: as a joint effort of experts in their various fields to study road accidents and find out the factors leading to them, and how such information could be made use of in bringing about improvements in road safety, and to make proposals and participate in road safety promotion. The investigation work will be intended to reveal the nature of accidents stage by stage, and to lay particular emphasis on matters such as road conditions at the time of accident, action taken by drivers and personal injuries.

Already at the outset of the investigations it is essential to decide that the task of investigation group would not include matters related to determining the guilty party; that is the task of the local police.

Accidents are investigated by accident category:

1. Fatal accidents.

2. Personal injury accidents.

3. Accidents involving pedestrian or cyclist.

4. Accidents involving heavy vehicles.

5. School transport accidents.

6. Other accidents.

\section{Composition of investigation group}

The composition of an investigation, when summoned to the scene of an accident, in Lithuania must be such that each field in the spectrum of the members' expertise is represented and, depending on the circumstances, specialists from other fields may also be included. Usually there should be four members: a police officer, a vehicle expert, a traffic specialist and a physician.

Investigation group should consist of several members - one member from each sector: police officers, vehicle specialists, traffic specialists, physicians, psychologists, railway specialists, vehicle body specialists and external aid. In the case of specific bus accidents, there may arise the need to call in a bus body's expert. The investigation team should be entitled to consult, when necessary, other specialists (e.g. psychologists, neurologists). When necessary, vehicles may be towed to a suitable garage in order to carry out technical inspections.

As becomes apparent from the above, the idea is to bring together the very best of expertise in the various fields from among authorities.

\section{The tasks of the investigation groups}

There is some variation as to the tasks of the investigation groups and individual team members. Standard procedure is, however, that the investigation team must scrutinize the following matters:

- the collision and its aftermath,

- the bearing safety devices (or the lack of them) had on the consequences,

- the circumstances which led to the accident, details concerning the people involved and their contribution to the accident having taken place, the technical condition of the vehicle(s) and how it/they behaved, and the conditions relating to the traffic environment.

With the above information as the basis, and using the definitions laid out in the investigation plan, the investigation team is expected to be able to come up with an estimate as to the causal factors which, in the end, led to the accident taking place.

In addition to giving consideration as to the accident factors, the investigation group is also expected to consider and propose measures for improving the situation as a result of observations. These proposals may be directed at legislation, education, training, information, supervision, vehicles, and the environment.

Each member is provided with an checklist form for his particular investigation sector. The purpose is to fill out the forms for every accident investigated; this is required for statistical reasons. When necessary, the team members make observations concerning other matters as well.

Then, at the final meeting concerning a case, the investigation group analyses the data produced by their investigation, and draws up a final report.

Tasks of the investigation groups vary according to the investigation schedules:

1. Before the collision: characteristics and actions of parties involved; condition and behaviour of vehicle; characteristics and conditions of traffic environment; progress of the accident by reconstruction.

2. During the collision: collision points; safety of vehicle; injuries to people; effect of safety equipment; effect of environment.

3. After the collision: rolling over/spinning of vehicles; first aid.

4. Further assessments of: causes of accident, prevention possibilities; necessary improvement measures. 


\section{Objects of investigation}

The investigation work of the groups can be directed at different accident categories. The following are examples of factors which have been taken into account when selecting cases to be investigated [5]:

- the importance of reducing the death toll on the roads;

- the need to obtain more information concerning problem sectors;

- the need to deepen investigation;

- the need to be able to produce investigation results which can be generalized;

- the need to provide the basic necessities for investigation work.

The investigation schedule for every year can be included in the following accident categories as reported to the police:

a. Fatal road accidents

All fatal road accidents are investigated throughout the country with the exception of those involving the death of a single pedestrian or cyclist.

b. Road accidents involving police vehicles

All road accidents which involve a police vehicle and cause personal injury and extensive damage to property are investigated throughout the country.

c. Road accidents involving road maintenance vehicles

All road accidents which involve vehicles used for road maintenance purposes and which cause personal injury and extensive damage to property are investigated throughout the country.

d. Road accidents involving a school transport vehicle

All road accidents which involve school transport vehicles and cause personal injury are investigated throughout the country.

e. Road accidents involving lorries with trailers All road accidents which involve lorries with trailers and which cause personal injury and extensive damage to property are investigated in selected counties.

f. Road accidents causing personal injury

All road accidents which take place in the centre of the selected towns and which result in personal injury are investigated.

g. Road accidents involving cyclists and mopedists All road accidents involving cyclists and mopedists are investigated in the selected towns.

h. Rear-end collision

All rear-end collisions occurring along selected street in selected town are investigated.

i. Other accidents

An investigation team may choose to investigate other accidents as well (e.g. at the request of the Head of County Administration).

\section{Procedures at the scene of the accident}

On arriving at the scene of the accident, the investigation group familiarizes itself with the general aspects of the accident as reported by the local police investigator and perhaps by the parties involved as well. Following this, the team members occupy themselves with gathering basic information within their fields of expertise. When necessary, members consult one another. For example, if the police representative hears a statement to the effect that the technical condition of a vehicle may have contributed to the accident taking place, he will pass on this piece of information to the vehicle specialist.

Once the basic data has been collected, the team members 'compare notes' for fit and try to build up a complete picture of the accident. The investigation work continues during the following days if necessary. It may be necessary, for example, to make a close study of the driver's knowledge of road regulations and his capabilities as a motorist. Likewise, the condition of the vehicle's brakes may need to be looked at more closely at a garage or the incident may need to be reconstructed where it actually happened.

The police member of the team has the task of collecting the general information regarding the accident and is primarily responsible for getting statements from the parties involved in the accident. Items of particular interest include driving licenses, purpose of the journey, events prior to the accident, how the accident occurred, observations and opinions of those involved. Interviews serve chiefly as a means of obtaining information concerning the personal characteristics, capabilities, knowledge of road regulations and attitudes possessed by the involved parties. Background studies on the involved parties reveal matters such as illnesses, whether the person is under medication, driving experience, mileage driven and traffic violations.

The vehicle specialist examines the vehicle's technical condition and the extent of internal and external damages to the vehicle. He gives his interpretation of the marks left by the vehicle and carries out certain calculations together with the traffic specialist.

During the examination of the vehicle's interior, particular attention is directed at marks left by the occupants. These marks, together with the sequence of events and the physician's report, provide the basis for arriving at conclusions as to the effect that the use of safety belts, for example, would have had on injuries sustained by the occupants. Collision marks on the car bodies are generally useful in reconstructing the mutual positions and travel directions of the vehicles at the moment of collision. The marks left on the road surface by the vehicles, on the other hand, indicate the positions of the vehicles on the road. 
The road specialist examines the condition of the road, sight distances and the geometric features of the road, and he draws a picture of the situation including a time schedule in seconds. Observations are also made regarding the surroundings, other traffic and previous accidents on the site in question.

Some of physician team members carry out investigations, some can be present at final meetings as specialists. Physicians determine the physical and mental capacities of drivers and what bearing this may have had on the accident having taken place. In addition, they determine the extent of injuries sustained by those involved in the accident, and with the assistance, primarily, of the vehicle specialist, they also determine the vehicle parts which caused the injuries. The physician members also determine what effect first aid and transport away from the scene of the accident have had on the consequences of the injuries.

On the basis of marks, statements, other data and the reconstruction calculations, the investigation team draws conclusions as to the various stages of the accident. Marks on vehicle bodies and on the road surface are seen as being important objective evidence. Statements given by eye witnesses have been observed to be contradictory at times; in addition, such statements have been known to change by the time a proper police examination is held. For this reason the practice is to question the involved parties as soon as possible.

Procedure at accident site is presented in Fig 2.

\begin{tabular}{|l|}
\hline The police officer interviews the driver. \\
The vehicle specialist inspects the vehicle. \\
The physician examines injuries. \\
The traffic specialist inspects the road. \\
The members of the investigation team perform: \\
a a basic information inspection of each special \\
examination if necessary.
\end{tabular}

Fig 2. Procedure at accident site

\section{Data analysis and final report}

In addition to their own investigations, the investigation team generally should get hold of the police inquest record and the forensic autopsy records of those killed in the accident. When necessary, additional documents related to the accident should be also obtained.

The investigated accident should be dealt with at the final meeting. The investigation team draws up the final report concerning the accident on the basis of the available data. This means that the team members present what data they have been able to obtain. These are then compared. If discrepancies arise, the various data are evaluated for reliability and efforts are made to see whether something else could be found to lend support to a certain item of data. If something is based on assumptions or is understood as being probable, this should be also mentioned in the final report. Thus, the final meeting is, by nature, a meeting for analyzing the investigation data and for deliberating as to the conclusions concerning the accident.

The investigation data consist of information gathered by team members from their own sectors of expertise, from independent sources, and dealing with the same subject; these features increase the chances of achieving true-to-life final reports of accidents.

The final report is an account of the course of event, the factors contributing to its having taken place, injuries sustained and what caused them, the effect of safety devices, remedies for improving safety, and measures carried out or proposed for improving local conditions. Generally, the final report should be available free of charge to the prosecutor, involved.

\section{Conclusions}

1. There is no comprehensive road accident investigation system with regard to traffic, driver, road and vehicle in Lithuania.

2. Road accident investigation should be targeted to evaluate three stages of collision: before, during and after.

3. Objects of investigation should be included in the following accident categories:

- fatal road accidents;

- road accidents causing personal injury;

- road accidents involving cyclists and mopedists;

- road accidents involving special transport;

- road accidents involving school buses.

4. Necessary preventive and improvement measures have to be carried out as a result of road accident investigation.

\section{References}

1. Statistical yearbook of Lithuania 2005 (Lietuvos statistikos metraštis 2005) - Department of Statistics to the Government of the Republic of Lithuania (Statistikos departamentas prie Lietuvos Respublikos Vyriausybès). Vilnius, 2005, p. 483-484 (in Lithuanian and English).

2. Sadauskas, V. Car passive safety study. Transportas (Transport Engineering), 2000, Vol XV, No 1, p. 41-47 (in Lithuanian).

3. Gunarson, S. O. Traffic Accident Prevention \& Reduction review. IATSS Research, Vol 20, No 2, 1996, p. 6-14.

4. Liikennevakuutuskeskus. The Finnish motor insurance system. Finnish Motor Insurers' Centre/ VALT, 1999, p. 1-7.

5. Sadauskas, V. Traffic safety strategies. Transport, 2003, Vol XVIII, No 2, p. 79-83. 